\title{
Formation of digital competencies in higher education as the basis for realization of sustainable development goals
}

\author{
Elena Razinkina, Elena Zima*, and Lyudmila Pankova \\ Peter the Great St. Petersburg Polytechnic University, 195251, St. Petersburg, Polytechnicheskaya, \\ 29, Russia
}

\begin{abstract}
The formation of digital competencies of citizens is currently a strategic goal for the Russian education system from the perspective of realization of sustainable development goals. The article considers the level model of digital competencies within higher education programmes at the $\mathrm{SPbPU}$, the key feature of which is a universal core that allows to facilitate sequential growth of competencies and implement flexible educational trajectories of students within the " $2+2+2$ " model.
\end{abstract}

\section{Introduction}

The 2030 Sustainable Development Goals, approved by the UN back in 2015, have doubtlessly predetermined the social, economic and environmental priorities in the development of strategic economic development programmes in the Russian Federation [1].

In 2017, Russia has launched a national programme "Digital Economy of the Russian Federation" [2] consisting of a large-scale set of federal projects aimed at the digital transformation of the Russian economy and society. Reaching the indicators of this national programme by 2024 is supposed to facilitate achievement of the main goal of digitalization: to improve the well-being, quality of life and safety of citizens in the digital economy. To this end, it is necessary to create legislation for application of digital technologies, modernization of digital infrastructure, creation and implementation of best digital practices in all the areas of the economy and public administration. It should be noted here that that creation and implementation of the digital economy ecosystem in Russia is impossible without the people possessing high levels of digital competencies necessary for life and work in a digital society. Without the conscious and controlled formation and development of digital competencies, it is impossible to achieve the stated goal of digitalization. That is why the federal project "Human Resources for the Digital Economy" plays a pivotal role in the implementation of the entire programme.

Currently, two problems related to the formation of digital competencies are particularly acute. On the one hand, there is already a clear barrier to Russia's transition to the digital economy, due to the gap between the real need for personnel trained to work within the Industry 4.0 and the available supply in the labor market. At the same time in the context of

${ }^{*}$ Corresponding author: zimaelena2015@gmail.com 
the universal digitalization of all key processes of the country's economy, a significant increase in the number of not only IT professionals, but also specialists with high levels of digital competence in different fields of professional activity is required. On the other hand, increasing the accessibility and quality of digital goods and services or ensuring the safety of citizens is impossible without a certain basic proficiency level in digital technologies, socalled digital literacy.

The lack of synchronization of digitalization processes in the field of labor and professional education in [3] is singled out as one of the main challenges in the development of the qualifications in the Russian Federation.

Considering this, the professional, and first of all, higher education, faces the task of consistently forming digital competencies within the framework of mastering the programmes of bachelor's, specialist's and master's degree. Meanwhile, it is important to note that higher education continues to perform the function of socialization, i.e. students should be given the opportunity to master digital competencies not only at the high, but also at the basic level. Moreover, in the context of universal digitalization, the active use of mobile devices and the Internet, possession of digital competencies is now necessary for obtaining the education itself.

Thus, the development of digital competencies is a prerequisite for the implementation of most of the sustainable development goals (SDGs) and, above all, the SDG 4 "Ensure inclusive and equitable quality education and promote lifelong learning opportunities for all". The COVID-19 pandemic has made this conclusion even more obvious [4].

\section{Methods and reference models}

Since currently there is no unified approach to the concept and composition of digital competencies, for the purposes of this study, the term "Digital Competencies" will be defined quite broadly as a range of competencies from the basics of digital literacy, necessary for a comfortable and safe existence in a digital society, to the most sought-after professional competencies in different fields of activity, due to the rapid development and widespread adoption of digital technologies, including IT specialists.

Digital transformations have sparked widespread debate about the need to reconsider the content of higher education, in particular, in formation and development of digital competencies of students, both at the level of universal competencies and general professional and professional competencies.

The specifics of formation of digital competencies are a topical problem and are considered in the research of many authors: Batova M.M. [5], Ershova T.V. and Ziva S.V. [6], Sharipova O.M. [7] and others.

Many Russian universities have done serious modernization of educational programmes aimed at developing "key competencies" in the context of large-scale digitalization of the economic, cultural and social spheres.

For example, the Higher School of Economics (HSE) University in 2020 adopted the Concept for the Development of Digital Competencies of Students at the HSE University [8], which interprets digital competencies as a set of competencies that facilitate the ability to work in the digital environment and with digital products, including various operations with data (creation, collection, processing, analysis), and to participate in the automation of various processes using computer technologies.

The HSE University considers important for the design of the model of students' mastering of digital competencies such principles of formation of digital competencies as the level nature and customization of educational programmes. This means that a minimal proficiency level in some or other digital competence is established for every educational programme. This takes into account the demands of the labor market. 
In the design of a model for the formation of digital competencies at the Peter the Great St. Petersburg Polytechnic University (SPbPU, Polytech), we took into account the European framework of digital competencies of the population, known as DigComp 2.1, which includes 21 competencies divided into five areas [9]. For each competence, the framework distinguishes 8 proficiency levels expressed through the education results based on the Bloom's taxonomy, which brings the DigiComp 2.1 closer to the models realized within the framework of Russian educational legislation.

The SPbPU model was based on the level structure of the competence model, which was established within the framework of the concept of the federal state educational standard (FSES) "3++": "category of competence - competence - indicator of achievement of competence - education result."

The second important principle in the development of the model of digital competencies at the SPbPU was the principle of level nature of development: from the competencies necessary for every citizen's comfortable and safe life in the digital environment, including for the construction of educational trajectories, to professional competencies, sought after in the conditions of the Industry 4.0.

Finally, the key principle of the SPbPU model is an isolation of a universal core for every level of digital competencies and for all the areas of training or a number of training areas, which facilitates the implementation of flexible educational trajectories of students within the model " $2+2+2$ ", taking into account the new opportunities that are opening up with the adoption of the Federal Law of May 26, 2021 No. 144-FZ.

\section{Results and discussions of the SPbPU digital competence model}

The new educational policy of the SPbPU enshrines the formation of digital competencies aimed at the integrated positioning of a creative personality in the new digital environment, as a mandatory result of mastering all educational programmes of bachelor's, specialist's, master's degree at the university. To this end, a separate category of competencies "Digital Ecosystem" has been introduced within the independently established educational standards in all areas of training provided at the SPbPU.

The digital ecosystem is a category of competencies that allow an SPbPU graduate to comfortably exist in a mixed ecosystem of interaction between people and digital agents, as well as transform it by developing and applying "end-to-end" digital technologies and their subtechnologies to the digital economy. Within the "Digital Ecosystem" category, Universal Competence (UC) has been introduced for each higher education level (Table 1), and it can be supplemented with other digital competencies in accordance with the specifics of educational programmes and the requirements of the labor market.

Table 1. Universal digital competences and achievement indicators.

\begin{tabular}{|c|c|c|}
\hline $\begin{array}{c}\text { Higher education } \\
\text { level }\end{array}$ & Bachelor's degree & Specialist's / Master's degree \\
\hline $\begin{array}{l}\text { Universal } \\
\text { competence }\end{array}$ & $\begin{array}{l}\text { Able to overcome the risks of the digital } \\
\text { environment and succeed in it }\end{array}$ & $\begin{array}{l}\text { Able to take part in digital transformations of } \\
\text { processes and models of professional } \\
\text { activity }\end{array}$ \\
\hline $\begin{array}{l}\text { Achievement } \\
\text { indicators }\end{array}$ & $\begin{array}{l}\text { Analyzes the processes of formation and } \\
\text { risks of the digital environment, identifying } \\
\text { trends in the development of key digital } \\
\text { technologies. } \\
\text { Uses open educational resources to build } \\
\text { individual educational trajectories tailored to } \\
\text { personal and professional needs. }\end{array}$ & $\begin{array}{l}\text { Applies "end-to-end" digital technologies in } \\
\text { professional activities, taking into account } \\
\text { resource constraints. } \\
\text { Participates in the modernization of processes } \\
\text { and/or models of professional activities to } \\
\text { effectively use digital technologies in solving } \\
\text { professional tasks. }\end{array}$ \\
\hline
\end{tabular}


The structure of any educational programme of the bachelor's (or specialist's) degree includes an end-to-end module, the "Digital Competence Module (Digital)" (9 credits total) focused on the formation of digital competencies. Disciplines, which are part of this module, are aimed at building competencies for working in the digital environment and with digital products, to automate processes through computer technologies, and facilitating the development of algorithmic thinking, skills in the application of modern digital tools and services. Digital competencies are integrated into all educational programmes of SPbPU at various levels: initial, "Digital Literacy", general professional, "Digital Culture", and professional, "Digital Professionalism".

Competencies of the "Digital Literacy" level characterize the individual's ability to identify in a digital environment and encompass basic knowledge, skills, and abilities related to digital hygiene, digital ethics, communication, technical and consumer security, the Internet of Things, XR, basics of data processing and analysis, as well as basic computer and Internet skills in the modern digital environment. An important component is the formation of a systemic idea of the current level and prospects for the development of "end-to-end" digital technologies. The initial level is mastered by all students, regardless of their major. The mandatory disciplines ("Digital Literacy," "Digital Industry Technology," "Digital Workshop"), aimed at forming the competencies of this level, are part of the "Polytech Core" module, which is the basic part of the educational programme of the bachelor's (specialist's) degree, mandatory for all students to learn regardless of their major (specialty).

The general professional level "Digital Culture" takes into account the needs in mastering the digital competencies of a particular major (specialty). The competencies of this level mainly determine the ability of the individual to work with large sets of structured and unstructured information (big data) and include the concepts of artificial intelligence, machine learning, neural networks, databases, the $\mathrm{R}$ programming language basics. Mandatory disciplines ("Digital Culture" and disciplines in digital technologies in professional activities) are part of the Polygroup Core module, which is mandatory within the Polygroup, a combination of majors (specialties) grouped by the level of physical and mathematical training, and/or within the module "Discipline by enlarged groups of specialties/majors (EGSM) / Major (specialty)".

Disciplines aimed at mastering the "Digital Professionalism" level are part of the module "Minor Disciplines" and form professional competencies that are subject-oriented and in demand in a specific major (profile) of training (specialization). The "Digital Professionalism" level skills encompass the skills of applying digital services and tools in professional activities.

In order to ensure the continuity of educational programmes of different levels, taking into account the greater differentiation of preparatory training of graduate students, the formation of digital competencies within the master's degree programmes is based on the following principles:

- development of digital competencies is carried out within the "Digital Professionalism" level;

- all educational programmes of the master's degree, regardless of the major, include the mandatory discipline "Digital Resources in Scientific Research", aimed at forming the universal competence of the "Digital Ecosystem" category;

- ability to participate in the digital transformation of processes and models in the future professional activities of students is formed by the inclusion of disciplines (modules) aimed at applying "end-to-end" digital technologies in professional activities into the master's degree programmes;

- mastering of digital competencies at the "Digital Literacy" and "Digital Culture" levels, if they are not formed during the bachelor's (specialist's) training, is expected through the study of relevant disciplines within the optional module in the online format. 
To increase motivation and engagement in the digital transformation of students within the mixed model of learning, online courses, developed both by SPbPU and other leading universities, are included in educational programmes. For example, the "Digital Competence Module (Digital)" in the bachelor's (specialist's) degree training includes online courses "Digital Literacy," "Digital Culture," "Cognitive Control Systems," "Basics of Neuroinformatics and Machine Learning," "Cyberphysical Systems: Theory and Applications," "Computer Engineering in Digital Design and Manufacturing," developed in 2020 by SPbPU together with partners (OMEGA Ltd. (St. Petersburg), St. Petersburg Innovation And Youth Initiatives Support Fund, Lenpolygraphmash Holding, Institute of Philosophy and Law of the Siberian Branch of the Russian Academy of Sciences and others), with the support of a grant from the Russian Ministry of Science, FP "Young professionals (increasing the competitiveness of professional education)". Online courses are correlated with the levels "Digital Literacy", "Digital Culture", and "Digital Professionalism". Their modular structure is fully consistent with the concept of the SPbPU digital competencies model and contributes as much as possible to the individualization of educational trajectories. Online courses are available at the Modern Digital Educational Environment portal: https://online.edu.ru/.

\section{Conclusions}

1. Formation of digital competencies is now a strategic challenge for the Russian higher education system in terms of achieving the sustainable development goals.

2. Implemented structure of the SPbPU digital competencies model, on the one hand, facilitates consistent build-up of competencies from basic digital literacy skills to professional competencies sought after in the conditions of the Industry 4.0, and on the other hand, allows to implement flexible educational trajectories of students within the model "2+2+2" taking into account the new opportunities opening up with the adoption of the Federal Law of May 26, 2021 No. 144-FZ, which is especially important for the multi-profile university.

\section{References}

1. The report on human development in the Russian Federation in 2016, https://ac.gov.ru

2. The national program "Digital Economy of the Russian Federation", https://digital.gov.ru

3. The strategy for the development of the Russian Federation's national qualifications system for the period up to 2030, https://nspkrf.ru

4. The sustainable development goals report (2020) https://unstats.un.org

5. M. M. Batova, Innovation Economics Problems, 4, 1573 (2019)

6. T. V. Ershova, S.V. Ziva, Information Society, 3, 4 (2018)

7. O. M. Sharipova, Creative Economy, 12, 2411 (2019)

8. The concept for the development of digital competencies of students at the HSE university, https://www.hse.ru

9. S. Carretero, R. Vuorikari, and Y. Punie, DigComp 2.1: The Digital Competence Framework for Citizens with eight proficiency levels and examples of use, http://publications.jrc.ec.europa.eu 